\title{
The role of the concept of LEAN management in modern business
}

\author{
Boban Melović ${ }^{1, *}$ Slavica Mitrović $^{2}$, Andrey Zhuravlev $^{3}$ and Natalia Braila ${ }^{4}$ \\ ${ }^{1}$ University of Montenegro, Faculty of Economics Podgorica, Jovana Tomasevica, 37, Podgorica, \\ Montenegro \\ ${ }^{2}$ University of Novi Sad, Faculty of Tehnical Sciences, Trg Dositeja Obradovica 6, Novi Sad, Serbia \\ ${ }^{3}$ Moscow State University of Civil Engineering, Yaroslavskoe shosse, 26, Moscow, 129337, Russia \\ ${ }^{4}$ Peter the Great St. Petersburg Polytechnic University, 195251, 29, Politekhnicheskaya st., Russia
}

\begin{abstract}
LEAN management is the concept of production management, product development and services that aims to create a true step change specifically targeted to the buyer or the goods or service. LEAN management is a dynamic process that uses knowledge and is focused on the customer. This is a process by which companies are continuously working to eliminate losses and value creation.
\end{abstract}

\section{Introduction}

"Edit your processes and increase the value of your company." James Womack and Daniel Jones, experts in LEAN manufacturing Although the concept of LEAN (LEAN philosophy) appeared in Japan at the end of XIX century, wider application is entered only after the Second World War. During this period, the country Japan, or relatively poor in natural resources, located on earthquake prone area and destroyed by war activities, with the aim of economic recovery and competitiveness in the market, should be distinguished from competitors with high quality products and shorter delivery time, with the possession of very small amounts of necessary resources (natural, financial, human). For this reason, it was necessary to engage in scientific and technological research at a high level, whose results were later to be implemented in industrial processes.

LEAN concept represents Toyota's Production System (TPS - Toyota Product System) or the mode of production and its creator Taiichi Ohno of is considered, the head of Toyota's manufacturing plant in the postwar period. Today the name of the LEAN concept, is defined by Professor James Womack (James P. Womack), Daniel Jones (Daniel T. Jones) and Daniel Rosa (Daniel Roos), and is presented in the book "The machine that changed the world". Generally speaking, LEAN represents a way of thinking and a set of principles, defined for the purpose of effective and efficient organization of the production process (or services) and supply, with the elimination of all activities that do not add value to the product, or represent losses as well as striving for continual improvement of the system. In

* Corresponding author: bobanm@ac.me 
addition to this, one of the definitions of this concept as follows: the LEAN production system, which allows the supply only what is needed, when needed and in the required quantity [1]. Storage excessive amount of inventory, or the amount of inventories that are not required to support basic processes, is considered the main loss and primary aim of elimination [2].

The leader Toyota, Taiichi Ohno and Shigeo Shingo (hired consultant) have defined the seven largest group losses incurred in the business processes of the organization and the effect of raising the cost of products, and they do not add value.

Womack and Jones believe that less than 5 percent of activities that add value to the product, and that about $35 \%$ of activities that do not add value, but they are necessary. In the end, about 60 percent of the activity is in a completely unnecessary activities and those that are the complete loss.

These seven groups of loss are [3]:

- Overproduction,

- Waiting time in the processes and inactivity of workers and equipment, waiting time for a product,

- Transport,

- Excessive processing,

- Stocks of raw materials, semi-finished products,

- Unnecessary movement of labor, equipment and materials and

- Frequent errors, the occurrence of rejects and finishing.

These losses added some authors and inadequate processes of product design, which does not meet the requirements of users, untapped intellectual potential of workers and missed opportunities.

\section{Key kind of wastage in the work process}

LEAN management experts have defined seven key types of waste. These types of scattering are [4]:

1. Excessive production

- Create a product that can not be placed on the market.

- Perform the operations that are not necessary

- Creating documentation that no claim or which shall not be later used

- Poor estimates sales ie. market demand

- Sending instructions by too many people (or vice versa)

- Production of "just in case"

2. Transpot

- Unnecessary movement of materials between operations or between storage areas

- Poor communication and information flow

- Communication failures, data loss, incompatibility, the unreliability of information

3. Waiting / congestion

- Waiting time between operations of materials, machines that workers hold are available or hold material (poor planning of production)

- Waiting for data, test results, information, decisions, signatures, permits and the like.

- Awaiting delivery (e.g., late raw materials and the like.)

4. Excessive processing

- Oversized facilities, poor or no technological equipment, preparatory-final time, cleaning between processing

- Previsto processing

- In deep processing 
- Poor design i.e. design products that require too much processing steps (too complex product)

5. Inventories

- Large inventories associated with excessive production ("frozen capital" in warehouses)

6. Unnecessary movements

- Improper machine, unnecessary displacement of workers

- People who have to leave their positions to get to the necessary information

- Handmade in order to compensate for a lack of production

7. Broke

- Interruption flow due to an error, unnecessary time, cost and space for analysis and elimination

- Incomplete, inaccurate or incomplete information

- Taking account of that waste, we conclude that the conditions for the implementation of this concept:

- Establishing a system of direct supply by a small number of trusted and reliable supplier,

- Smaller-sized production batches (lots)

- Establishing and aligning production capacities,

- Multifunctional (universal) trained workers,

- Specialized production lines,

- Preventive maintenance system, and

- Uninterrupted flow of cases through the system work.

\section{The benefits of the application of LEAN management}

There are many benefits of using this concept, and the authors are distinguished:

1. Reduction in inventory levels and therefore bound capital,

2. Less scrap and finishing,

3. Reducing the number of suppliers, the ability to standardize procurement and harmonize the quality of procurement,

4. Reduced paperwork and administration and

5. To increase the level of productivity and overall efficiency of workers and equipment.

In order to eliminate losses, i.e. those activities that do not add value to the product and more efficient development of the process, these authors Womack and Jones, defined five key principles in the implementation of LEAN concepts [5]:

Value - determining the value of products, defined by the user; focus on meeting customer demands for products or services, at the right time and in an appropriate manner;

Value stream - establishing a series of activities over the work material and information from 'the supplier's supplier' to 'member users, "the purpose of efficient implementation of the process of determining user requirements, determine the possible product defects and implementation of improvements, ie removing all steps that does not add value to the product or service;

Flow - synchronized and a steady flow of products through the value chain to the end user through all the activities that add value to the product (service) in a manner which eliminates barriers, poor quality, spoilage and delays in the way of the product;

Pull - start production when users expressed the need for the product; signaling the need for the product next factor in the supply chain (in the direction of users - manufacturer - supplier);

Perfection - continuous pursuit of eliminating all losses; cyclic trajectory seeking perfection through the elimination of the losses, which the user does not want to pay the cost of the product and put added value of the same product. 
Lean management, therefore, represents a major step forward. Observing the concept of project management, then the transition from management on lean management, was as great as the step transition from project management to portfolio management. The biggest advantage of LEAN methods the connection between reducing costs and improving productivity and quality. In LEAN-in, all the energy and creativity have been organized so as to strive to better optimize and add value to the user side. This includes other things such as price, delivery time, maintenance costs, environmental taxes and more. Also, it happens to improve and internal factors such as safety, hygiene and ergonomics.

\section{Conclusion}

By applying LEAN management improves the flexibility of the organization and the quality of operations, reduces the goods in stock, improves the functioning of the process, eliminating activities that do not add value, it is better utilization of human resources, improving the organization of work and employee satisfaction, and ultimately, the most important, increases customer satisfaction.

The organization, therefore, should be oriented towards customers and coordinate all activities that do not bring value to customers [6]. Taking care of the natural resources, LEAN management avoids all superfluous in the chain of production. This approach is the administration of which, based on the fact that for a 'which more with less ". The purpose of the LEAN management is to lead the organization of the world's leading organizations in terms of quality, through a constant effort that the number of defective products is reduced to the lowest possible level. However, about LEAN management has different opinions, for some this is the perfect model of governance for any organization, while others believe that this is a bad approach to management, because after many years of application do not achieve satisfactory results.

Based on the foregoing, it can be concluded that LEAN management is the business philosophy of the organization, aimed at reducing operating costs, i.e. all losses, to thereby increase the success of the organization.

\section{References}

1. Lean Lexicon. Lean Enterprise Institute Inc (2008)

2. T. Goldsby, R. Martichenko, J. Ross Publishing 1, 25-28 (2005)

3. D. T. Jones, P. Hines, N. Rich, International Journal of Psychology 27, 13-19 (1997)

4. http://project-management-srbija.com/upravljanje-kvalitetom/osnove-lean-proizvodnje (2016)

5. J. P. Womack, D. T. Jones, A division of Simon \& Schuster 57, 85-88 (2003)

6. B. Melović, Faculty of Economics Podgorica 13, 32-37 (2007) 